OPEN ACCESS

Edited by:

Fabrizio Sanna,

University of Cagliari, Italy

Reviewed by:

Federico Turkheimer,

King's College London,

United Kingdom

Chia-Liang Tsai,

National Cheng Kung

University, Taiwan

*Correspondence:

Meiqi Zhang

mzhang2@springfieldcollege.edu

Specialty section

This article was submitted to

Pathological Conditions,

a section of the journal

Frontiers in Behavioral Neuroscience

Received: 29 June 2020

Accepted: 15 September 2020

Published: 22 October 2020

Citation:

Zhang M, Liu Z, Ma H and Smith DM

(2020) Chronic Physical Activity for

Attention Deficit Hyperactivity Disorder and/or Autism Spectrum Disorder in

Children: A Meta-Analysis of

Randomized Controlled Trials.

Front. Behav. Neurosci. 14:564886

doi: 10.3389/fnbeh.2020.564886

\section{Chronic Physical Activity for Attention Deficit Hyperactivity Disorder and/or Autism Spectrum Disorder in Children: A Meta-Analysis of Randomized Controlled Trials}

\author{
Meiqi Zhang ${ }^{1 *}$, Zhan Liu ${ }^{1}$, Hongtao $\mathrm{Ma}^{2}$ and Daniel M. Smith ${ }^{1}$ \\ 'Department of Physical Education and Health Education, Springfield College, Springfield, MA, United States, ${ }^{2}$ School of \\ Arts, Beijing Sport University, Beijing, China
}

Purpose: To explore the effects of physical activity (PA) intervention on executive function (EF) and motor skills (MS) among children with attention deficit hyperactivity disorder and/or autism spectrum disorder (ASD).

Methods: Relevant studies were sourced from PubMed, Web of Science, EMBASE, Cochrane Library, CNKI and Wanfang Data. Only randomized controlled trials (RCT) were included based upon the following criteria: (1) participants were children and clinically diagnosed with ADHD/ASD, (2) intervention strategies were identified as chronic physical activity, and (3) EF (e.g., cognitive flexibility) and/or MS (e.g., gross motor skills) were measured at baseline and post-intervention and compared with an eligible control group.

Results: Eleven studies involving 346 participants were finally identified. PA elicited significant improvements in EF and MS in children with ADHD/ASD. Regarding changes in the EF of participants, PA showed a great improvement in overall EF [standardized mean difference (SMD): 0.90, 95\% confidence interval (Cl) 0.49-1.30, $p<0.00001$ ], inhibitory control (SMD: 1.30, 95\% Cl 0.58-2.02, $p=0.0004$ ) and cognitive flexibility (SMD: 0.85, 95\% Cl 0.42-1.29, $p=0.0001$ ), but no significant improvement in working memory (SMD: $0.28,95 \% \mathrm{Cl}-0.15-0.71, p=0.20$ ). Significant improvements were also found with respect to gross motor skills (SMD: 0.80, 95\% Cl 0.30-1.30, $p=0.002$ ), but no significant changes were found in fine motor skills (SMD: $0.30,95 \% \mathrm{Cl}-0.91-1.52$, $p=0.62)$.

Conclusion: Chronic PA interventions may promote EF and MS in children with ADHD/ASD, especially in inhibitory control, cognitive flexibility, and gross motor skills. However, PA interventions seemed to have insignificant effects on working memory and fine motor skills to children with ADHD/ASD.

PROSPERO registration number: CRD42019118622

Keywords: ADHD, ASD, executive function, motor skills, physical activity, children 


\section{INTRODUCTION}

Attention deficit hyperactivity disorder (ADHD) and autism spectrum disorder (ASD) are the most common neurodevelopmental disorders in children (AmericanPsychiatric-Association, 2013). Epidemiological studies showed that the current estimated prevalence for ADHD is $~ 5 \%$ of children (Polanczyk et al., 2007, 2014; Smith et al., 2016) and for ASD is $1.5-1.68 \%$ of children (Baio, 2014; Lyall et al., 2017) worldwide. Children with ASD have apparent deficits in social communication and repetitive patterns of behaviors (Fombonne, 2009), while children with ADHD have manifested symptoms such as difficulty paying attention, excessive activity, or difficulty controlling behavior in a developmentally inappropriate manner (Dunn and Kronenberger, 2003; Cormier, 2008; Lange et al., 2010; American-Psychiatric-Association, 2013). These problems are significantly detrimental to their quality of life (Ross, 2006; Mayes et al., 2008) and even persist in their later life (Klassen et al., 2004; Agranat-Meged et al., 2005; Birnbaum et al., 2005). Although there are significant differences in the core symptoms, the similarities between ADHD and ASD have been supported by clinical studies (Simonoff et al., 2008; Murray, 2010; Grzadzinski et al., 2011; Hanson et al., 2013; Craig et al., 2016; Gordon-Lipkin et al., 2018).

Impairments of cognitive and behavioral competencies (Gapin and Etnier, 2010) in ADHD and ASD are common and need to be thoroughly addressed, especially executive function (EF) performance and motor competence. EF comprises a series of self-regulatory cognitive processes, such as monitoring and controlling both thought and goal-directed behaviors (Diamond, 2013; Craig et al., 2015, 2016). Overall EF impairments have been considered as central deficits in ADHD/ASD; children within the group exhibited weakness in inhibitory control, cognitive flexibility, and working memory (Courchesne et al., 1994; Hughes et al., 1994; Ozonoff, 1995; Pascualvaca et al., 1998). Also, EF performance is closely related to motor skills (MS) because both of the disorders have similar underlying processes, which include sequencing, monitoring, and planning (Roebers and Kauer, 2009; Yazd et al., 2015). MS can be classified into gross motor and fine motor skills, which are necessary for activities in daily living. A range of MS impairments have been identified in children with ADHD/ASD (Bhat et al., 2011; Pan, 2014); this might be related to the insufficient level of neurotransmitters (Kaiser et al., 2015), which indicated the critical need for interventions to promote optimal motor and overall development.

$\mathrm{EF}$ and motor development have been shown to be promising endophenotypes in ASD/ADHD (Russell, 1997; Biederman

Abbreviations: ADHD, Attention Deficit Hyperactivity Disorder; ASD, Autism Spectrum Disorder; BOT-2, Bruininks-Oseretsky Test of Motor Proficiency, Ed.2; CI, Confidence Intervals; CNS, Central Nervous System; SM1, Contralateral Primary Somatosensory Cortex; DLPFC, Dorsolateral Prefrontal Cortex; EF, Executive Function; GRADE, Grading of Recommendations Assessment, Development; MD, Mean Difference; MS, Motor Skills; MABC-2, Movement Assessment Battery for Children; PA, Physical Activity; PMA, Pre-Motor Area; RCT, Randomized Control Trials; SMD, Standardized Mean Difference; SMA, Supplementary Motor Area; TGMD-2, Test of Gross Motor Development-2; VLPFC, Ventrolateral Prefrontal Cortex; PM1, Primary Sensorimotor Cortex; PFC, Prefrontal Cortex; SPC, Superior parietal lobule. et al., 2004; Willcutt et al., 2005), which depends on lifestyle and strategies. Physical activity (PA) is defined as any bodily movement produced by skeletal muscles that results in energy expenditure (Caspersen et al., 1985; DePauw and Gavron, 2005), with regular and adequate levels of PA leading to improve both cognitive function (Pontifex et al., 2013; Piepmeier et al., 2015; Benzing et al., 2018) and motor skills (Fisher et al., 2005; Wrotniak et al., 2006) for children. The Centers for Disease Control and Prevention in the U.S also recommends that children should participate in moderate to vigorous-intensity physical activity at least $60 \mathrm{~min}$ per day and high-intensity exercise at least three times per week (Piercy et al., 2018). However, compared with typically developing children, relatively less attention has been directed to the study of PA in children with ADHD/ASD. Given that previous studies in typically developing children generally reported PA benefits EF and MS, especially in inhibitory control (Berenguer et al., 2018) and gross motor development (Wrotniak et al., 2006; Lopes et al., 2011), PA has the potential to be used as a strategy to improve EF and MS in children with ADHD/ASD.

In summary, current literature has provided valuable information on the effects of PA on EF and MS in children with ADHD/ASD. However, it remains unclear specifically how PA affects EF and MS of children with ADHD/ASD that would be useful to clinicians and informative for future research. Therefore, the purpose of this study was to investigate the effects of PA on EF and MS in children with ADHD/ASD and explore the mechanisms of applying PA to EF and MS based on the meta-analytic findings.

\section{METHODS}

This meta-analysis is reported according to the Preferred Reporting Items for Systematic reviews and Meta-analyses (PRISMA). This study is registered with PROSPERO (CRD42019118622) and the protocol has been published in a peer-reviewed journal.

\section{Search Strategy}

We performed a search of PubMed, Web of Science, EMBASE, Cochrane Library, CNKI and Wanfang Data from inception to August 2020. We considered all the English and Chinese studies. We used key phrases and Medical Subject Heading (MeSH) terms as follows: physical activity, exercise, executive function, cognitive function, inhibitory control, inhibition, working memory, cognitive flexibility, motor skill, gross motor skill, fine motor skill, motor behaviors, motor functions, $A D H D, A D D$, and ASD. In addition, the reference lists of included studies were examined for other potentially eligible studies.

\section{Inclusion and Exclusion Criteria}

Articles were eligible for inclusion if the study design was a randomized controlled trial (RCT); if the participants were children and adolescents with ADHD and/or ASD; if the studies reported at least one outcome of interest measured at preand post-intervention. In these studies, the experimental group received a chronic PA intervention program with no limitation 
on the types, frequency, and intensity, while the control group was treated by sedentary resting or received no treatment. The outcomes of interest consisted of three subfunctions of EF (i.e., working memory, inhibitory control, and cognitive flexibility) and two subtypes of motor skills (i.e., gross motor skills and fine motor skills).

\section{Data Extraction}

The titles and abstracts of studies were initially screened by two independent review authors. Related studies were recorded and managed using Endnote software. Following this, the two authors put their screened studies together and determined suitable studies with the inclusion criteria. When a disagreement happened, a third author participated to solve the problem by discussion to make a final consensus. For the studies that met the inclusion criteria, full articles were obtained for further analysis. The two authors separately extracted data from the published works using standard data extraction forms. Any inconsistencies in the process of data extraction were solved by checking original texts and reaching an agreement through discussion. Information on trial design, characteristics of the subjects, PA protocol, and relevant results were noted according to a redesigned form. We recorded the name of the first author and the year of publication for each article; the sample sizes, the ages, and gender of participants; the measurements; and the interventions for each group. When data were insufficient or inapplicable, we attempted to contact the authors by e-mail. A total of two authors were contacted (Yazd and Liu), and only Liu replied.

\section{Risk of Bias Assessment and GRADE Assessment}

The Cochrane Collaboration's tools were used to check the random sequence generation, allocation concealment, blinding, incomplete outcome data, selective reporting and other bias. Each item was determined as a high-risk, low-risk, or unclear grade by the two authors. The grading of evidence quality and risk of bias by two authors were compared, and the third reviewer was consulted if the consensus was not attained.

\section{Data Analysis and Synthesis}

We used Revman 5.3 (The Cochrane Collaboration, Software Update, Oxford, UK) to conduct the data analysis. The continuous outcomes were expressed as mean difference (MD) with 95\% Confidence Intervals (CIs). When the MD of the outcomes is large or the unit is different, the standardized mean difference (SMD) was used. The SMD and 95\% CI were calculated and then interpreted as suggested by Cohen (2013): $0.00-0.19$ (trivial); $0.20-0.49$ (small); 0.50-0.79 (moderate); and $\geq 0.80$ (large).

If $p>0.10, \mathrm{I}^{2}<50 \%$, it will be considered that heterogeneity is low enough and a meta-analysis can be conducted with a fixedeffect model. If $p<0.10, \mathrm{I}^{2}>50 \%$, it will be considered as a high level of heterogeneity, and a random effect model will be used.

\section{RESULTS}

\section{Search Results}

The flow diagram illustrating the search and screening process is shown in Figure 1. The initial database search identified a total of 627 articles. After duplicates removed, 208 articles were further identified and screened, and 419 non-relevant articles were excluded. A total of 53 remaining articles were read in full text. At this point, 42 additional articles were excluded for the following reasons: (1) study types, (2) reduplicative participants, (3) natural observations, (4) animal studies, (5) none of required data. Eleven papers were rendered as a final sample.

\section{Characteristics of Included Trails}

A total of 346 participants were included in the analysis, of which 174 (about 50.28\%) participants underwent a PA intervention. The characteristics of subjects, type of intervention, intensity and duration, and measurements from the included studies were described in Table 1. The PA intervention ranged from 6 weeks to 1.5 year in duration and occurred one to five times per week. The duration of per session of PA intervention ranged from 30 to 90 min per session.

\section{Risk of Bias Among the Selected Articles}

The evaluation results are shown in Figure 2.

\section{Executive Function}

Eight studies with 329 subjects assessed executive function as outcomes (Figure 3). The pooled SMD of overall EF was 0.90 (95\% CI $0.49-1.30, p<0.0001)$, with high heterogeneity $\left(I^{2}=\right.$ $80 \%, p<0.00001)$. Regarding the subfunctions of EF, the SMD was 0.28 (95\% CI $-0.14-0.71, p=0.19)$ for working memory, with moderate heterogeneity $\left(I^{2}=53 \%, p=0.09\right) ; 1.30(95 \%$ CI $0.58-2.02, p=0.0004)$ for inhibitory control, with large heterogeneity $\left(I^{2}=85 \%, p<0.00001\right)$; and 0.85 (95\% CI $0.42-$ $1.29, p=0.0001)$ for cognitive flexibility, with low heterogeneity $\left(I^{2}=9 \%, p=0.33\right)$.

\section{Motor Skills}

Six studies with 161 subjects assessed motor skills as outcomes (Figure 4). The pooled SMD of overall MS was 0.61 (95\% CI $0.02-1.19, p=0.04)$, with moderate heterogeneity $\left(I^{2}=77 \%, p\right.$ $<0.0001)$. Regarding the subfunctions of MS, the pooled SMD was 0.80 (95\% CI $0.30-1.30, p=0.002)$ for gross motor skills, with small heterogeneity $\left(I^{2}=43 \%, p=0.18\right)$; and the SMD was 0.30 (95\% CI $-0.91-1.52, p=0.62$ ) for fine motor skills, with large heterogeneity $\left(I^{2}=88 \%, p<0.0001\right)$. Unfortunately, there was no significant change in fine motor skills as compared with control groups.

\section{DISCUSSION}

The present meta-analysis revealed that PA could significantly improve $\mathrm{EF}$ and $\mathrm{MS}$ of $\mathrm{ADHD} / \mathrm{ASD}$ children in terms of cognitive flexibility, inhibitory control, and gross motor skills. However, our analysis did not provide strong evidence to the effectiveness of PA on working memory and fine motor skills in ADHD/ASD children. 


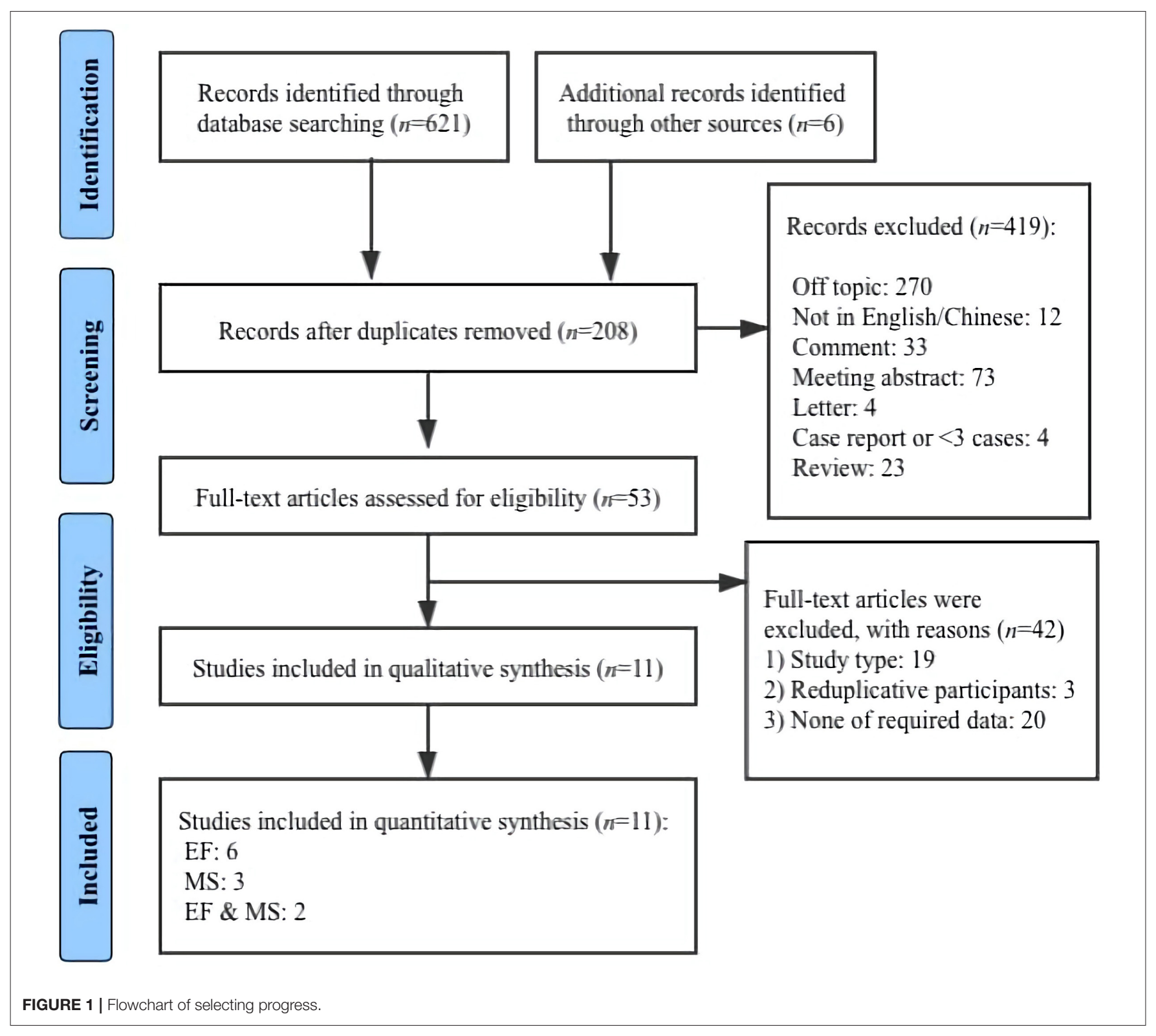

Our findings are aligned with previous studies on the efficacy of PA on improving some aspects of cognition of individuals with ASD/ADHD (Cerrillo-Urbina et al., 2015; Tan et al., 2016) and are consistent with the results of motor skills from the systematic reviews (Den Heijer et al., 2017). The clinical PA programs, however, are shown to be relatively less efficacious in the magnitude of improvements in the working memory compared with earlier results of a systematic review (SuarezManzano et al., 2018) and a previous RCT study (Smith et al., 2016). Also, we did not find a significant improvement in fine motor skills, which is not consistent with the results from another recent systematic review (Jeyanthi et al., 2019).

Deficits in EF are believed to be an important origin of ADHD/ASD symptoms (Diamond, 2013). Available evidence, however, indicates that some deficits in executive function could be improved by PA intervention as some RCTs (Smith et al., 2016; Jeyanthi et al., 2019) and meta-analysis (Xue et al., 2019) show. Our work extends the results of previous studies and finds that PA interventions are beneficial to inhibitory control and cognitive flexibility in children with ADHD/ASD. The underlying mechanisms of PA-induced EF improvements might be related to two aspects, which are the promotion of attention allocation (especially in the dorsolateral prefrontal cortex; DLPFC) and changes in the concentration of neurotransmitters. Children who participate in PA are more likely to be affected by contextual interference, which the interference in performance and learning that arises from performing one task in the context of other tasks. For example, in the exercise of table tennis (Benzing et al., 2018), the children had to continuously modify their body direction and location to effectively catch the ball in 
TABLE 1 | Characteristics of the included trials.

\begin{tabular}{|c|c|c|c|c|c|}
\hline References & $\begin{array}{l}\text { Main characteristic of the } \\
\text { subjects }\end{array}$ & ADHD/ASD & Instruments & Intervention arm & Control arm \\
\hline $\begin{array}{l}\text { Srinivasan et al. } \\
(2015)\end{array}$ & $\begin{array}{l}\text { PA: mean age was } 7.88 \pm 2.56 \\
n=12,83.3 \% \text { male; } \\
\text { CON: mean age was } 7.36 \pm \\
2.02, n=12,91.7 \% \text { male. }\end{array}$ & ASD & MS: BOT-2 & $\begin{array}{l}\text { Rhythm PA ( } 45 \text { min/session, } 4 \\
\text { times/week); } 8 \text { weeks }\end{array}$ & None \\
\hline Tse et al. (2019) & $\begin{array}{l}\text { PA: mean age was } 10.11 \pm \\
1.20, n=19,73.7 \% \text { male; } \\
\text { CON: mean age was } 9.81 \pm \\
1.17, n=21,85.7 \% \text { male }\end{array}$ & ASD & $\begin{array}{l}\text { EF: False alarm error, Digit } \\
\text { span backward }\end{array}$ & $\begin{array}{l}\text { Basketball skill learning (45 } \\
\text { min/session, } 2 \text { times/week); } 12 \\
\text { weeks }\end{array}$ & None \\
\hline Pan et al. (2017) & $\begin{array}{l}\text { PA: mean age was } 9.68 \pm 1.61 \\
n=11,100 \% \text { male; } \\
\text { CON: mean age was } 8.49 \pm \\
1.76, n=11,100 \% \text { male }\end{array}$ & ASD & $\begin{array}{l}\text { EF: WCST; } \\
\text { MS: BOT-2 }\end{array}$ & $\begin{array}{l}\text { Integrated PA (70 min/session, } 2 \\
\text { times/week);12 weeks }\end{array}$ & Waitlist \\
\hline $\begin{array}{l}\text { Bustamante et al. } \\
\text { (2016) }\end{array}$ & $\begin{array}{l}\text { PA: mean age was } 9.4 \pm 2.2, n \\
=19,68 \% \text { male; } \\
\text { CON: mean age was } 8.7 \pm 2, n \\
=16,69 \% \text { male }\end{array}$ & ADHD & $\begin{array}{l}\text { EF: Stop-signal inhibition } \\
\text { task, Automated working } \\
\text { memory assessment } \\
\text { system }\end{array}$ & $\begin{array}{l}\text { Physical games + modified aerobic } \\
\text { sports ( } 90 \text { min/session, } 5 \\
\text { times/week); } 10 \text { weeks }\end{array}$ & Sedentary control \\
\hline $\begin{array}{l}\text { Liu and Yang } \\
\text { (2018) }\end{array}$ & $\begin{array}{l}\text { PA: } n=32,50 \% \text { male; } \\
\text { CON: } n=32,50 \% \text { male }\end{array}$ & ADHD & $\begin{array}{l}\text { EF: Corsi block tapping } \\
\text { test }\end{array}$ & $\begin{array}{l}\text { Orienteering activity ( } 35 \\
\text { min/session, } 3 \text { times/week); } 14 \\
\text { weeks }\end{array}$ & None \\
\hline Pan et al. (2019) & $\begin{array}{l}\text { PA: mean age was } 9.08 \pm 1.43 \\
n=15,100 \% \text { male; } \\
\text { CON: mean age was } 8.9 \pm 1.66 \\
n=15,100 \% \text { male }\end{array}$ & ADHD & $\begin{array}{l}\text { EF: WCST; Stroop test } \\
\text { MS: TGMD-2 }\end{array}$ & $\begin{array}{l}\text { Table tennis + group games + } \\
\text { conditioning training (70 } \\
\text { min/session, } 2 \text { times/week); } 12 \\
\text { weeks }\end{array}$ & None \\
\hline Yazd et al. (2015) & $\begin{array}{l}\text { PA: } 6 \sim 12 \text { years, } n=12,83.3 \% \\
\text { male; } \\
\text { CON: } 6 \sim 12 \text { years, } n=12 \\
83.3 \% \text { male }\end{array}$ & $\mathrm{ADHD}$ & MS: BOT-2 & $\begin{array}{l}\text { Motor training }+ \text { drug therapy }(3 \\
\text { times/week);6 weeks }\end{array}$ & Drug therapy \\
\hline $\begin{array}{l}\text { Mirzaei and } \\
\text { Aslankhani, } 2015\end{array}$ & $\begin{array}{l}\text { PA: mean age was } 9.5, n=4 \text {, } \\
100 \% \text { male; } \\
\text { CON: mean age was } 9.5, n=4 \\
100 \% \text { male }\end{array}$ & ASD & MS: TGMD-2 & $\begin{array}{l}\text { Motor exercises ( } 45 \mathrm{~min} / \text { session, } 1 \\
\text { time/week); } 12 \text { weeks }\end{array}$ & None \\
\hline Kadri et al. (2019) & $\begin{array}{l}\text { PA: mean age } 14.5 \pm 3.5, n= \\
\text { 20, } 90 \% \text { male; } \\
\text { CON: mean age } 14.2 \pm 3, n= \\
20,90 \% \text { male }\end{array}$ & ADHD & EF: Stroop test & $\begin{array}{l}\text { Taekwondo exercise + regular PE } \\
\text { classes ( } 50 \text { min/session, } 2 \\
\text { times/week); } 1.5 \text { year }\end{array}$ & Regular PE classes \\
\hline $\begin{array}{l}\text { Benzing and } \\
\text { Schmidt (2019) }\end{array}$ & $\begin{array}{l}\text { PA: mean age was } 10.46 \pm 1.3 \\
n=11,86.4 \% \text { male; } \\
\text { CON: } 10.39 \pm 1.44, n=12 \\
81.8 \% \text { male }\end{array}$ & ADHD & $\begin{array}{l}\text { EF: Flanker task, Color } \\
\text { span backwards } \\
\text { MS: German motor test }\end{array}$ & $\begin{array}{l}\text { Exergaming ( } 30 \text { min/session, } 3 \\
\text { times/week); } 8 \text { weeks }\end{array}$ & Waitlist \\
\hline $\begin{array}{l}\text { Memarmoghaddam } \\
\text { et al. (2016) }\end{array}$ & $\begin{array}{l}\text { PA: mean age was } 8.31 \pm 1.29 \text {, } \\
n=19,100 \% \text { male; } \\
\text { CON: mean age was } 8.29 \pm \\
1.31, n=17,100 \% \text { male }\end{array}$ & ADHD & $\begin{array}{l}\text { EF: Stroop test, Go/No go } \\
\text { test }\end{array}$ & $\begin{array}{l}\text { Aerobic exercise + goal directed } \\
\text { exercise ( } 90 \text { min/session, } 3 \\
\text { times/week); } 8 \text { weeks }\end{array}$ & None \\
\hline
\end{tabular}

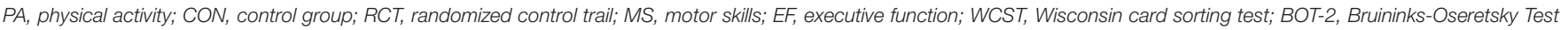
of Motor Proficiency; TGMD-2, Test of Gross Motor Development-2.

one scenario but need to lob the ball in another. These nonpredetermined and rarely repeated tasks place higher demands on executive processes (Carey et al., 2005). Thus, the processing of pertinent information is likely to lead to greater learning. In addition, $\mathrm{EF}$ is associated with the prefrontal cortex, mainly on the frontal pole, ventrolateral prefrontal cortex (VLPFC), and DLPFC (Diamond, 2013). Children with ADHD/ASD were identified with significantly unstable neurotransmitters system and lower concentration of monoamine neurotransmitters like dopamine (Dresel et al., 2000; Krause et al., 2004) and norepinephrine (Bymaster et al., 2002), which may lead to hypo-arousal level (Jeyanthi et al., 2019) in PFC. Strong evidence reveals that $\mathrm{PA}$ is effective in stimulating arousal levels in prefrontal cortex and activating neurotransmitter systems like dopamine (Foley and Fleshner, 2008), which may explain our results that $\mathrm{PA}$ intervention could promote $\mathrm{EF}$ in children with ADHD/ASD.

Notably, contrary to previous studies (Hillman et al., 2005; Kamijo et al., 2011; Koutsandréou et al., 2016), this study showed that PA intervention had favorable effects on overall EF in children with ADHD/ASD; the effects of PA on working memory, however, were still limited. Similar to 
Random sequence generation (selection bias)

Allocation concealment (selection bias)

Blinding of participants and personnel (performance bias)

Blinding of outcome assessment (detection bias)

Incomplete outcome data (attrition bias)

Selective reporting (reporting bias)

Other bias
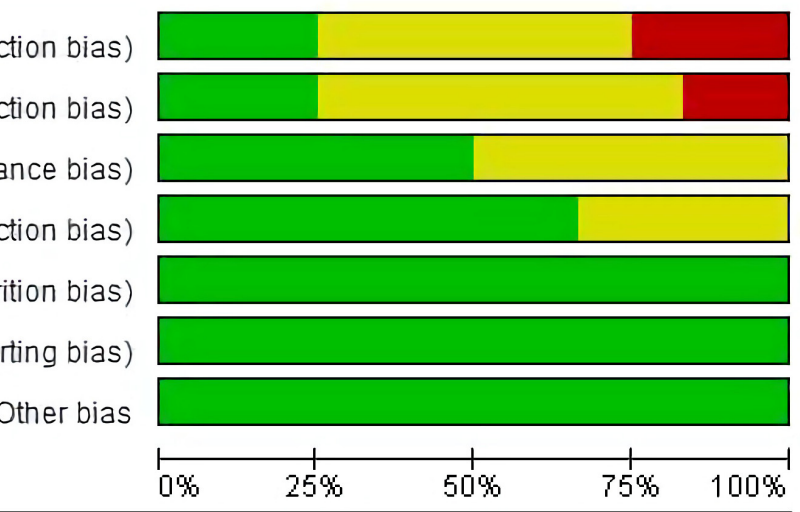

Low risk of bias

Unclear risk of bias

High risk of bias

FIGURE 2 | Risk of bias assessment for the included studies.

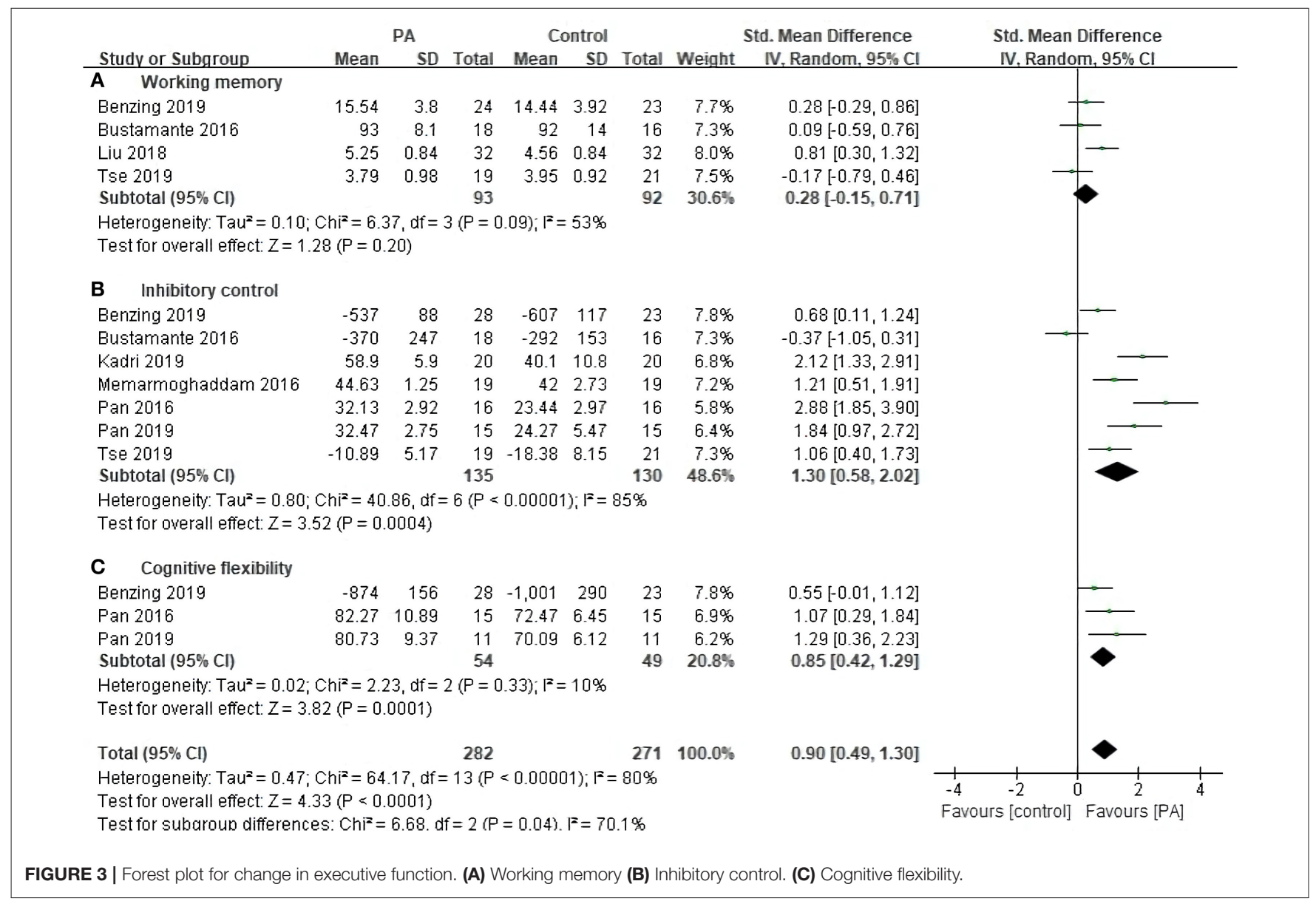

our findings, a recent meta-analysis of RCTs by Xue et al. (2019) identified the minor benefits of PA interventions on working memory. The inconsistent results could partly be explained by the differences among intervention methods, as well as the difference in the baseline of participants. Further researchers would need to consider more about the intervention program design (e.g., types of PA, intensity, frequency, and duration) and the characteristics of children (especially with 


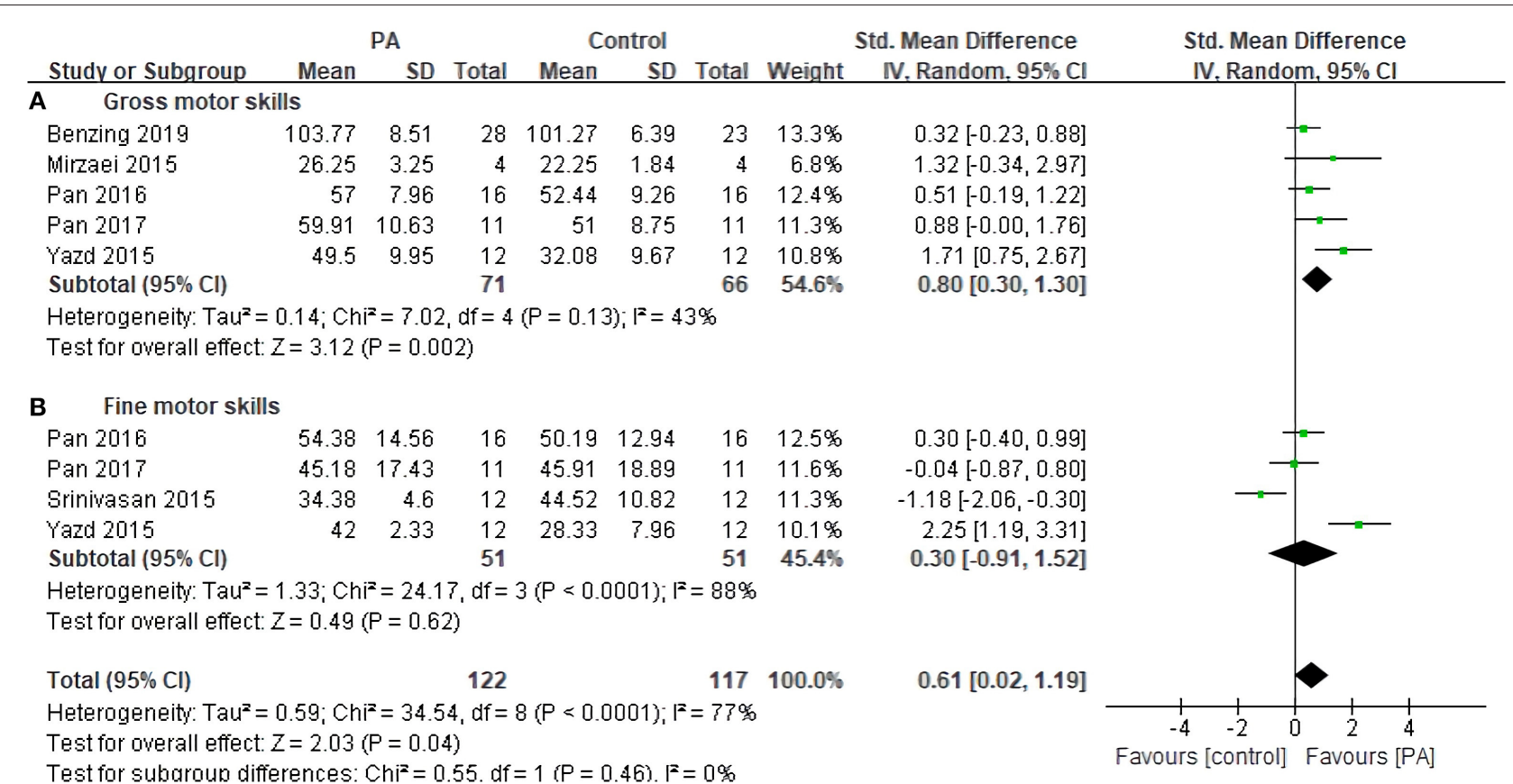

FIGURE 4 | Forest plot for change in motor skills. (A) Gross motor skills. (B) Fine motor skills.

respect to age and the severity of disorders), which may impact trial results.

Delayed motor development has been widely found in children with ADHD/ASD (Thapar and Cooper, 2016). To children with ADHD/ASD, impaired MS are not only impacting their daily activities, but it is also a barrier to social interaction and community integration with peers (Pan et al., 2017). Our findings are strongly supported by most of the reviewed studies (Pan, 2014; Pan et al., 2017) that overall MS improved after PA interventions. Several brain regions are believed to be crucial for acquiring and executing skilled motor behaviors including cerebellum, basal ganglia, and regional motor cortex of the frontal lobe (Ungerleider et al., 2002; Luft and Buitrago, 2005; Halsband and Lange, 2006), and neurotransmitter system. In addition, the theory about arousal level as aforementioned might also be used to explain the mechanism. As the previous study demonstrated that there were negative correlations between physical activity and brain arousal level on motor competence, especially with lower performance, in children with ADHD (Berger, 2012).

A potential reason for the no significant changes in fine motor skills in children with ADHD/ASD after physical activity interventions might be related to variability in the intensity of PA interventions. Given that psychostimulant drugs (e.g., Methylphenidate) have demonstrated positive effects on fine motor skills in children with ADHD/ASD by modulating neurotransmitters, fine motor skills could be improved with increasing neurotransmitter levels. Moderate to high-intensity PA has also been recognized as an effective way to enhance the level of neurotransmitters (Vučković et al., 2010; Lin and Kuo, 2013) and the plasticity of the central nervous system (CNS). However, all the included studies in this meta-analysis mentioned the duration and frequency of interventions but did not report the exercise intensity used in the studies, which may partially account for the null findings regarding fine motor skills. Additionally, molecular studies (Ferguson and Cada, 2004; Yu et al., 2010) reported gross motor performance appears to be normal in $\mathrm{ADHD}$ but there were structural deficits displayed in fine motor skills, which might further explain our findings. Previous fMRI evidence showed that complex finger movements could activate more domains in the brain (e.g., SM1, SMA, PMA, PFC, SPC, cerebellum, and basal ganglia) than simple finger movements (Chang et al., 2002). However, most of the interventions included in our study were fundamental movements (e.g., treadmill training, exergames). Although we cannot simply conclude by the findings in animal models, it is still reminding that future studies and clinical applications should consider adding more exercise about fine motor skills in training programs.

To the best of our knowledge, this meta-analysis is the first study to quantitively compare the effectiveness of chronic PA and non-intervention on EF (e.g., working memory, cognitive flexibility, and inhibitory control) and MS (e.g., gross motor skills and fine motor skills) in children with ADHD/ASD. One strength of the study is the strict inclusion principles, which could increase the validity of causal inferences. Also, subgroup analysis was conducted to explore the detailed changes of physical activity on motor skills and executive functions in children with ADHD/ASD might be another important feature of the study. 
However, some limitations were still present in the evaluation. First, the different measurements of the included studies may lead to high heterogeneity in this meta-analysis. Second, a relatively small number of studies in motor skills in comparison to EF studies included in the review may affect the findings of our analysis. As a result, the effects of PA on MS remain to be determined and further explored. Third, the results of the metaanalysis might be limited by the lack of large sample, multi-center and long-term studies in the included studies, which may have some limitations in guiding clinical applications.

In conclusion, the present meta-analysis supports the positive effects of PA on EF and MS in children with ADHD/ASD, especially in inhibitory control, cognitive flexibility, and gross motor skills. These findings indicate that PA can be implemented in children with $\mathrm{ADHD} / \mathrm{ASD}$ as an alternative training modality. However, we found insignificant effects of PA interventions on working memory and fine motor skills in children with

\section{REFERENCES}

Agranat-Meged, A. N., Deitcher, C., Goldzweig, G., Leibenson, L., Stein, M., and Galili-Weisstub, E. (2005). Childhood obesity and attention deficit/hyperactivity disorder: a newly described comorbidity in obese hospitalized children. Int. J. Eating Disord. 37, 357-359. doi: 10.1002/eat.20096

American-Psychiatric-Association (2013). Diagnostic and Statistical Manual of Mental Disorders (DSM-5®). Washington, DC: American Psychiatric Publishing.

Baio, J. (2014). Prevalence of autism spectrum disorder among children aged 8 years-autism and developmental disabilities monitoring network. $M M W R$ Surveill. Summ. 67, 1-23. doi: 10.15585/mmwr.ss6706a1

Benzing, V., Chang, Y. K., and Schmidt, M. (2018). Acute physical activity enhances executive functions in children with ADHD. Sci. Rep. 8:12382. doi: 10.1038/s41598-018-30067-8

Benzing, V., and Schmidt, M. (2019). The effect of exergaming on executive functions in children with ADHD: a randomized clinical trial. Scand. J. Med. Sci. Sports 29, 1243-1253. doi: 10.1111/sms.13446

Berenguer, C., Roselló, B., Colomer, C., Baixauli, I., and Miranda, A. (2018). Children with autism and attention deficit hyperactivity disorder. relationships between symptoms and executive function, theory of mind, and behavioral problems. Res. Dev. Disabil. 83, 260-269. doi: 10.1016/j.ridd.2018.10.001

Berger, D. S. (2012). Pilot study investigating the efficacy of tempo-specific rhythm interventions in music-based treatment addressing hyper-arousal, anxiety, system pacing, and redirection of fight-or-flight fear behaviors in children with autism spectrum disorder (ASD). J. Biomusic. Eng. 2:M110902. doi: 10.4303/jbe/M110902

Bhat, A. N., Landa, R. J., and Galloway, J. C. (2011). Current perspectives on motor functioning in infants, children, and adults with autism spectrum disorders. Phys. Ther. 91, 1116-1129. doi: 10.2522/ptj.20100294

Biederman, J., Monuteaux, M. C., Doyle, A. E., Seidman, L. J., Wilens, T. E., Ferrero, F., et al. (2004). Impact of executive function deficits and attentiondeficit/hyperactivity disorder (ADHD) on academic outcomes in children. J. Consult. Clin. Psychol. 72, 757-766. doi: 10.1037/0022-006X.72.5.757

Birnbaum, H. G., Kessler, R. C., Lowe, S. W., Secnik, K., Greenberg, P. E., Leong, S. A., et al. (2005). Costs of attention deficit-hyperactivity disorder (ADHD) in the US: excess costs of persons with ADHD and their family members in 2000. Curr. Med. Res. Opin. 21, 195-205. doi: 10.1185/030079904X20303

Bustamante, E. E., Davis, C. L., Frazier, S. L., Rusch, D., Fogg, L. F., Atkins, M. S., et al. (2016). Randomized controlled trial of exercise for ADHD and disruptive behavior disorders. Med. Sci. Sports Exerc. 48, 1397-1407. doi: 10.1249/MSS.0000000000000891

Bymaster, F. P., Katner, J. S., Nelson, D. L., Hemrick-Luecke, S. K., Threlkeld, P. G., Heiligenstein, J. H., et al. (2002). Atomoxetine increases extracellular levels of norepinephrine and dopamine in prefrontal cortex of rat: a
ADHD/ASD. Future studies should investigate the effects of PA in ADHD/ASD longitudinally through multicenter RCT with large sample sizes.

\section{DATA AVAILABILITY STATEMENT}

All datasets generated for this study are included in the article/supplementary material.

\section{AUTHOR CONTRIBUTIONS}

This study was conceptualized by MZ, ZL, HM, and DS. DS contributed to collecting data. Analyzing data and drafting the manuscript was by MZ and ZL. HM contributed to revising and approving the final version of the manuscript. All authors contributed to the article and approved the submitted version.

potential mechanism for efficacy in attention deficit/hyperactivity disorder. Neuropsychopharmacology 27, 699-711. doi: 10.1016/S0893-133X(02)00346-9

Carey, J. R., Bhatt, E., and Nagpal, A. (2005). Neuroplasticity promoted by task complexity. Exerc. Sport Sci. Rev. 33, 24-31. Available online at: https:// journals.lww.com/acsm-essr/fulltext/2005/01000/neuroplasticity_promoted_ by_task_complexity.5.aspx

Caspersen, C. J., Powell, K. E., and Christenson, G. M. (1985). Physical activity, exercise, and physical fitness: definitions and distinctions for health-related research. Public Health Rep. 100, 126-131.

Cerrillo-Urbina, A. J., García-Hermoso, A., Sánchez-López, M., Pardo-Guijarro, M. J., Santos Gómez, J. L., and Martínez-Vizcaíno, V. (2015). The effects of physical exercise in children with attention deficit hyperactivity disorder: a systematic review and meta-analysis of randomized control trials. Child Care Health Dev. 41, 779-788. doi: 10.1111/cch.12255

Chang, S., Feng, G., and Kong, X. (2002). A contrast study of the simple and complex finger tapping for motor activation by using functional MRI. J. Clin. Radilol. 1.

Cohen, J. (2013). Statistical Power Analysis for the Behavioral Sciences. Hillsdale, NJ: Academic Press.

Cormier, E. (2008). Attention deficit/hyperactivity disorder: a review and update. J. Pediatr. Nurs. 23, 345-357. doi: 10.1016/j.pedn.2008.01.003

Courchesne, E., Townsend, J., Akshoomoff, N. A., Saitoh, O., YeungCourchesne, R., Lincoln, A. J., et al. (1994). Impairment in shifting attention in autistic and cerebellar patients. Behav. Neurosci. 108, 848-865. doi: 10.1037/0735-7044.108.5.848

Craig, F., Lamanna, A. L., Margari, F., Matera, E., Simone, M., and Margari, L. (2015). Overlap between autism spectrum disorders and attention deficit hyperactivity disorder: searching for distinctive/common clinical features. Autism Res. 8, 328-337. doi: 10.1002/aur.1449

Craig, F., Margari, F., Legrottaglie, A. R., Palumbi, R., De Giambattista, C., and Margari, L. (2016). A review of executive function deficits in autism spectrum disorder and attention-deficit/hyperactivity disorder. Neuropsychiatr. Dis. Treat 12, 1191-1202. doi: 10.2147/NDT.S1 04620

Den Heijer, A. E., Groen, Y., Tucha, L., Fuermaier, A. B., Koerts, J., Lange, K. W., et al. (2017). Sweat it out? The effects of physical exercise on cognition and behavior in children and adults with ADHD: a systematic literature review. J. Neural Trans. 124, 3-26. doi: 10.1007/s00702-016-1593-7

DePauw, K. P., and Gavron, S. J. (2005). Disability Sport. Champaign, IL: Human Kinetics.

Diamond, A. (2013). Executive functions. Annu. Rev. Psychol. 64, 135-168. doi: 10.1146/annurev-psych-113011-143750

Dresel, S., Krause, J., Krause, K. H., Lafougere, C., Brinkbäumer, K., Kung, H. F., et al. (2000). Attention deficit hyperactivity disorder: binding of [99mTc]TRODAT-1 to the dopamine transporter before and 
after methylphenidate treatment. Eur. J. Nucl. Med. 27, 1518-1524. doi: $10.1007 / \mathrm{s} 002590000330$

Dunn, D. W., and Kronenberger, W. G. (2003). Attention-deficit/hyperactivity disorder in children and adolescents. Neurol. Clin. 21, 933-940. doi: 10.1016/S0733-8619(03)00009-4

Ferguson, S. A., and Cada, A. M. (2004). Spatial learning/memory and social and nonsocial behaviors in the spontaneously hypertensive, Wistar-Kyoto and Sprague-Dawley rat strains. Pharmacol. Biochem. Behav. 77, 583-594. doi: $10.1016 /$ j.pbb.2003.12.014

Fisher, A., Reilly, J. J., Kelly, L. A., Montgomery, C., Williamson, A., Paton, J. Y., et al. (2005). Fundamental movement skills and habitual physical activity in young children. Med. Sci. Sports Exerc. 37, 684-688. doi: 10.1249/01.MSS.0000159138.48107.7D

Foley, T. E., and Fleshner, M. (2008). Neuroplasticity of dopamine circuits after exercise: implications for central fatigue. J. Neuromol. Med. 10, 67-80. doi: $10.1007 /$ s12017-008-8032-3

Fombonne, E. (2009). Epidemiology of pervasive developmental disorders. Pediatr. Res. 65, 591-598. doi: 10.1203/PDR.0b013e31819e7203

Gapin, J., and Etnier, J. L. (2010). The relationship between physical activity and executive function performance in children with attention-deficit hyperactivity disorder. J. Sport Exerc. Psychol. 32, 753-763. doi: 10.1123/jsep.32.6.753

Gordon-Lipkin, E., Marvin, A. R., Law, J. K., and Lipkin, P. H. (2018). Anxiety and mood disorder in children with autism spectrum disorder and ADHD. Pediatrics 141:e20171377. doi: 10.1542/peds.2017-1377

Grzadzinski, R., Di Martino, A., Brady, E., Mairena, M. A., O’Neale, M., et al. (2011). Examining autistic traits in children with ADHD: does the autism spectrum extend to ADHD? J. Autism Dev. Disord. 41, 1178-1191. doi: $10.1007 /$ s10803-010-1135-3

Halsband, U., and Lange, R. K. (2006). Motor learning in man: a review of functional and clinical studies. J. Physiol. Paris. 99, 414-424. doi: 10.1016/j.jphysparis.2006.03.007

Hanson, E., Cerban, B. M., Slater, C. M., Caccamo, L. M., Bacic, J., and Chan, E. (2013). Brief report: Prevalence of attention deficit/hyperactivity disorder among individuals with an autism spectrum disorder. J. Autism Dev. Disord. 43, 1459-1464. doi: 10.1007/s10803-012-1677-7

Hillman, C. H., Castelli, D. M., and Buck, S. M. (2005). Aerobic fitness and neurocognitive function in healthy preadolescent children. J. Med. Sci. Sports Exerc. 37, 1967-1974. doi: 10.1249/01.mss.0000176680.79702.ce

Hughes, C., Russell, J., and Robbins, T. W. (1994). Evidence for executive dysfunction in autism. Neuropsychologia 32, 477-492. doi: 10.1016/0028-3932(94)90092-2

Jeyanthi, S., Arumugam, N., and Parasher, R. K. (2019). Effect of physical exercises on attention, motor skill and physical fitness in children with attention deficit hyperactivity disorder: a systematic review. J. Atten. Defic. Hyperact. Disord. 11, 125-137. doi: 10.1007/s12402-018-0270-0

Kadri, A., Slimani, M., Bragazzi, N. L., Tod, D., and Azaiez, F. (2019). Effect of taekwondo practice on cognitive function in adolescents with attention deficit hyperactivity disorder. Int. J. Environ. Res. Public Health 16:204. doi: 10.3390/ijerph16020204

Kaiser, M. L., Schoemaker, M. M., Albaret, J. M., and Geuze, R. H. (2015). What is the evidence of impaired motor skills and motor control among children with attention deficit hyperactivity disorder (ADHD)? Systematic review of the literature. J. Res. Dev. Disabil. 36, 338-357. doi: 10.1016/j.ridd.2014.09.023

Kamijo, K., Pontifex, M. B., O’Leary, K. C., Scudder, M. R., Wu, C. T., Castelli, D. M., et al. (2011). The effects of an afterschool physical activity program on working memory in preadolescent children. J. Dev. Sci. 14, 1046-1058. doi: 10.1111/j.1467-7687.2011.01054.x

Klassen, A. F., Miller, A., and Fine, S. (2004). Health-related quality of life in children and adolescents who have a diagnosis of attention-deficit/hyperactivity disorder. Pediatrics. 114, e541-e547. doi: 10.1542/peds.2004-0844

Koutsandréou, F., Wegner, M., Niemann, C., and Budde, H. (2016). Effects of motor versus cardiovascular exercise training on children's working memory. J. Med. Sci. Sports Exerc. 48, 1144-1152. doi: 10.1249/MSS.0000000000000869

Krause, K. H., Dresel, S. H., Krause, J., la Fougere, C., and Ackenheil, M. (2004). The dopamine transporter and neuroimaging in attention deficit hyperactivity disorder. J. Neurosci. Biobehav. Rev. 27, 605-613. doi: 10.1016/j.neubiorev.2003.08.012
Lange, K. W., Reichl, S., Lange, K. M., Tucha, L., and Tucha, O. (2010). The history of attention deficit hyperactivity disorder. Attent. Defic. Hyperact. Disord. 2, 241-255. doi: 10.1007/s12402-010-0045-8

Lin, T. W., and Kuo, Y. M. (2013). Exercise benefits brain function: the monoamine connection. J. Brain Sci. 3, 39-53. doi: 10.3390/brainsci3010039

Liu, Y., and Yang, N. (2018). An experimental study of the effect of orienteering exercises on the cognitive ability of children with ADHD. Chin. J. Special Educ. 221, 39-44.

Lopes, V. P., Rodrigues, L. P., Maia, J. A., and Malina, R. M. (2011). Motor coordination as predictor of physical activity in childhood. Scand. J. Med. Sci. Sports. 21, 663-669. doi: 10.1111/j.1600-0838.2009.01027.x

Luft, A. R., and Buitrago, M. M. (2005). Stages of motor skill learning. J. Mol. Neurobiol. 32, 205-216. doi: 10.1385/MN:32:3:205

Lyall, K., Croen, L., Daniels, J., Fallin, M. D., Ladd-Acosta, C., Lee, B. K., et al. (2017). The changing epidemiology of autism spectrum disorders. J. Annu. Rev. Public Health 38, 81-102. doi: 10.1146/annurev-publhealth-031816-044318

Mayes, R., Bagwell, C., and Erkulwater, J. (2008). ADHD and the rise in stimulant use among children. Harv. Rev. Psychiatry 16, 151-166. doi: $10.1080 / 10673220802167782$

Memarmoghaddam, M., Torbati, H. T., Sohrabi, M., Mashhadi, A., and Kashi, A. (2016). Effects of a selected exercise programon executive function of children with attention deficit hyperactivity disorder. J. Med. Life. 9, 373-379.

Mirzaei, M., and Aslankhani, M. A. (2015). The effect of a selected physical activity program using expert and novice modeling on acquisition and retention of gross motor skills in autistic children. Int. J. Sport Stud. 5, 665-671.

Murray, M. J. (2010). Attention-deficit/hyperactivity disorder in the context of autism spectrum disorders. Curr. Psychiatry Rep. 12, 382-388. doi: 10.1007/s11920-010-0145-3

Ozonoff, S. (1995). Executive Functions in Autism: Learning and Cognition in Autism. Boston, MA: Springer.

Pan, C. Y. (2014). Motor proficiency and physical fitness in adolescent males with and without autism spectrum disorders. Autism 18, 156-165. doi: $10.1177 / 1362361312458597$

Pan, C. Y., Chang, Y. K., Tsai, C. L., Chu, C. H., Cheng, Y. W., and Sung, M. C. (2017). Effects of physical activity intervention on motor proficiency and physical fitness in children with ADHD: an exploratory study. J. Atten. Disord. 21, 783-795. doi: 10.1177/1087054714533192

Pan, C. Y., Tsai, C. L., Chu, C. H., Sung, M. C., Huang, C. Y., and Ma, W. Y. (2019). Effects of physical exercise intervention on motor skills and executive functions in children with ADHD: a pilot study. J. Atten. Disord. 23, 384-397. doi: 10.1177/1087054715569282

Pascualvaca, D. M., Fantie, B. D., Papageorgiou, M., and Mirsky, A. F. (1998). Attentional capacities in children with autism: Is there a general deficit in shifting focus? J. Autism Dev. Disord. 28, 467-478. doi: 10.1023/A:1026091809650

Piepmeier, A. T., Shih, C.-H., Whedon, M., Williams, L. M., Davis, M. E., Henning, D. A., et al. (2015). The effect of acute exercise on cognitive performance in children with and without ADHD. J. Sport Health Sci. 4, 97-104. doi: 10.1016/j.jshs.2014.11.004

Piercy, K. L., Troiano, R. P., Ballard, R. M., Carlson, S. A., Fulton, J. E., Galuska, D. A., et al. (2018). The physical activity guidelines for Americans. JAMA 320, 2020-2028. doi: 10.1001/jama.2018.14854

Polanczyk, G., de Lima, M. S., Horta, B. L., Biederman, J., and Rohde, L. A. (2007). The worldwide prevalence of ADHD: a systematic review and metaregression analysis. Am. J. Psychiatry 164, 942-948. doi: 10.1176/ajp.2007.16 4.6.942

Polanczyk, G. V., Willcutt, E. G., Salum, G. A., Kieling, C., and Rohde, L. A. (2014). ADHD prevalence estimates across three decades: an updated systematic review and meta-regression analysis. Int. J. Epidemiol. 43, 434-442. doi: 10.1093/ije/dyt261

Pontifex, M. B., Saliba, B. J., Raine, L. B., Picchietti, D. L., and Hillman, C. H. (2013). Exercise improves behavioral, neurocognitive, and scholastic performance in children with attention-deficit/hyperactivity disorder. J. Pediatr. 162, 543-551. doi: 10.1016/j.jpeds.2012.08.036

Roebers, C. M., and Kauer, M. (2009). Motor and cognitive control in a normative sample of 7-year-olds. Dev. Sci. 12, 175-181. doi: 10.1111/j.1467-7687.2008.00755.x 
Ross, R. G. (2006). Psychotic and manic-like symptoms during stimulant treatment of attention deficit hyperactivity disorder. Am. J. Psychiatry 163, 1149-1152. doi: 10.1176/ajp.2006.163.7.1149

Russell, J. (1997). How Executive Disorders can Bring About an Inadequate'theory of Mind. Oxford: Oxford University Press.

Simonoff, E., Pickles, A., Charman, T., Chandler, S., Loucas, T., and Baird, G. (2008). Psychiatric disorders in children with autism spectrum disorders: prevalence, comorbidity, and associated factors in a populationderived sample. J. Am. Acad. Child Adolesc. Psychiatry 47, 921-929. doi: 10.1097/CHI.0b013e318179964f

Smith, S. D., Vitulano, L. A., Katsovich, L., Li, S., Moore, C., Li, F., et al. (2016). A randomized controlled trial of an integrated brain, body, and social intervention for children with ADHD. J. Atten. Disord. 24, 780-794. doi: 10.1177/1087054716647490

Srinivasan, S. M., Kaur, M., Park, I. K., Gifford, T. D., Marsh, K. L., and Bhat, A. N. (2015). The effects of rhythm and robotic interventions on the imitation/praxis, interpersonal synchrony, and motor performance of children with autism spectrum disorder (ASD): a pilot randomized controlled trial. Autism Res. Treat. 2015:736516. doi: 10.1155/2015/736516

Suarez-Manzano, S., Ruiz-Ariza, A., De La Torre-Cruz, M., and Martínez-López, E. J. (2018). Acute and chronic effect of physical activity on cognition and behaviour in young people with ADHD: a systematic review of intervention studies. Res. Dev. Disabil. 77, 12-23. doi: 10.1016/j.ridd.2018.03.015

Tan, B. W., Pooley, J. A., and Speelman, C. P. (2016). A meta-analytic review of the efficacy of physical exercise interventions on cognition in individuals with autism spectrum disorder and ADHD. J. Autism Dev. Disord. 46, 3126-3143. doi: $10.1007 / \mathrm{s} 10803-016-2854-\mathrm{x}$

Thapar, A., and Cooper, M. (2016). Attention deficit hyperactivity disorder. Lancet 387, 1240-1250. doi: 10.1016/S0140-6736(15)00238-X

Tse, C. Y. A., Lee, H. P., Chan, K. S. K., Edgar, V. B., Wilkinson-Smith, A., and Lai, W. H. E. (2019). Examining the impact of physical activity on sleep quality and executive functions in children with autism spectrum disorder: A randomized controlled trial. Autism, 23, 1699-1710. doi: 10.1177/1362361318823910

Ungerleider, L. G., Doyon, J., and Karni, A. (2002). Imaging brain plasticity during motor skill learning. Neurobiol. Learn. Mem. 78, 553-564. doi: 10.1006/nlme.2002.4091
Vučković, M. G., Li, Q., Fisher, B., Nacca, A., Leahy, R. M., Walsh, J. P., et al. (2010) Exercise elevates dopamine D2 receptor in a mouse model of Parkinson's disease: in vivo imaging with [18F] fallypride. J. Move. Disord. 25, 2777-2784. doi: $10.1002 / \mathrm{mds} .23407$

Willcutt, E. G., Doyle, A. E., Nigg, J. T., Faraone, S. V., and Pennington, B. F. (2005). Validity of the executive function theory of attentiondeficit/hyperactivity disorder: a meta-analytic review. Biol. Psychiatry 57, 1336-1346. doi: 10.1016/j.biopsych.2005.02.006

Wrotniak, B. H., Epstein, L. H., Dorn, J. M., Jones, K. E., and Kondilis, V. A. (2006). The relationship between motor proficiency and physical activity in children. Pediatric 118, e1758-e1765. doi: 10.1542/peds.2006-0742

Xue, Y., Yang, Y., and Huang, T. (2019). Effects of chronic exercise interventions on executive function among children and adolescents: a systematic review with meta-analysis. Br. J. Sports Med. 53, 1397-1404. doi: 10.1136/bjsports-2018-099825

Yazd, S. N., Ayatizadeh, F., Dehghan, F., Machado, S., and Wegner, M. (2015). Comparing the effects of drug therapy, perceptual motor training, and both combined on the motor skills of school-aged attention deficit hyperactivity disorder children. CNS Neurol. Disord. Drug Targets. 14, 1283-1291. doi: 10.2174/18715273156661511111 23501

Yu, Q., Lei, G., Castellanos, F. X., Forssberg, H., and Heijtz, R. D. (2010). Deficits in fine motor skills in a genetic animal model of ADHD. J. Behav. Brain Funct. 6:51. doi: 10.1186/1744-9081-6-51

Conflict of Interest: The authors declare that the research was conducted in the absence of any commercial or financial relationships that could be construed as a potential conflict of interest.

Copyright (c) 2020 Zhang, Liu, Ma and Smith. This is an open-access article distributed under the terms of the Creative Commons Attribution License (CC BY). The use, distribution or reproduction in other forums is permitted, provided the original author(s) and the copyright owner(s) are credited and that the original publication in this journal is cited, in accordance with accepted academic practice. No use, distribution or reproduction is permitted which does not comply with these terms. 